\title{
Infratentorial MRI Findings in Rasmussen Encephalitis Suggest Primary Cerebellar Involvement
}

\author{
Johannes T. Reiter, ${ }^{*}$ Bastian David, MSc, ${ }^{*}$ Selma Enders, MSc, Conrad C. Prillwitz, MD, Tobias Bauer, BSc, \\ Deniz Atalay, MD, Anna Tietze, MD, PhD, Angela M. Kaindl, MD, PhD, Vera Keil, MD, \\ Alexander Radbruch, MD, PhD, JD, Bernd Weber, MD, PhD, Albert J. Becker, MD, PhD, \\ Christian E. Elger, MD, PhD, Rainer Surges, MD, PhD, and Theodor Rüber, MD
}

Neurol Neuroimmunol Neuroinflamm 2021;8:e1058. doi:10.1212/NXI.0000000000001058

\author{
Correspondence \\ Dr. Rüber \\ theodor.rueber@ukbonn.de
}

\begin{abstract}
\section{Background and Objective}

Rasmussen encephalitis (RE) is characterized by its unilateral cerebral involvement. However, both ipsi- and contralesional cerebellar atrophy have been anecdotally reported raising questions about the nature and extent of infratentorial findings. Using MRI, we morphometrically investigated the cerebellum and hypothesized abnormalities beyond the effects of secondary atrophy, implicating a primary involvement of the cerebellum by RE.
\end{abstract}

\section{Methods}

Voxel-based morphometry of the cerebellum and brainstem was conducted in 57 patients with $\mathrm{RE}$ and in 57 matched controls. Furthermore, patient-specific asymmetry indices (AIs) of cerebellar morphometry and fluid-attenuated inversion recovery (FLAIR) intensity were calculated. Using diffusion tensor imaging, the integrity of the cortico-ponto-cerebellar (CPC) tract was assessed. Finally, a spatial independent component analysis (ICA) was used to compare atrophy patterns between groups.

\section{Results}

Patients with RE showed bilateral cerebellar and predominantly ipsilesional mesencephalic atrophy $(p<0.01)$. Morphometric AIs revealed ipsilesional < contralesional asymmetry in 27 and ipsilesional $>$ contralesional asymmetry in 30 patients. In patients with predominant ipsilesional atrophy, morphometric AIs strongly correlated with FLAIR intensity AIs $(r=0.86$, $p<0.0001)$. Fractional anisotropy was lower for ipsilesional-to-contralesional CPC tracts than opposite tracts $(T=2.30, p<0.05)$. ICA revealed bilateral and strictly ipsi- and contralesional atrophy components in patients with $\mathrm{RE}(p<0.05)$.

\section{Discussion}

We demonstrated atrophy of the ipsilesional-to-contralesional CPC pathway and, consequently, interpret the loss of contralesional gray matter as secondary crossed cerebellar atrophy. The ipsilesional cerebellar atrophy, however, defies this explanation. Based on FLAIR hyperintensities, we interpret ipsilesional atrophy to be due to inflammation in the scope of a primary involvement of the cerebellum by RE. 


\section{Glossary}

$\mathbf{A I}=$ asymmetry index; $\mathbf{C O N}=$ controls; $\mathbf{C P C}=$ cortico-ponto-cerebellar; $\mathbf{D T I}=$ diffusion tensor imaging; $\mathbf{F A}=$ fractional anisotropy; FDR = false discovery rate; FLAIR = fluid-attenuated inversion recovery; FOD = fiber orientation distribution; FSL = FMRIB Software Library 6.0; FWE = family-wise error; GM = gray matter; ICA = independent component analysis; RE = Rasmussen encephalitis; SUIT = spatially unbiased infratentorial atlas template; VBM = voxel-based morphometry; $\mathbf{W M}=$ white matter.

Rasmussen encephalitis (RE) is a rare autoimmune disorder of the brain, characterized most prominently by progressive atrophy of a single cerebral hemisphere associated with neurologic deficits and intractable seizures. ${ }^{1,2}$ MRI serves as a crucial, noninvasive method in the diagnostic assessment and followup routine of patients with RE. ${ }^{2}$ Although known as cerebral disease, single case reports and small group studies have consistently reported the occurrence of cerebellar volume changes in individual patients, visible on MRI. ${ }^{3,4}$ In the vast majority of these patients, cerebellar atrophy was observed contralesional to the cerebral focus, which is in line with the concept of crossed cerebellar atrophy. ${ }^{3}$ This phenomenon describes an irreversible volume decline of the cerebellum secondary to a remote, supratentorial lesion and can most likely be explained by damage to the crossing cortico-ponto-cerebellar (CPC) pathway. ${ }^{5}$ However, cerebellar atrophy was occasionally identified in the ipsilesional hemisphere, which eludes explanation and raises the question of whether cerebral inflammation can spill over to the cerebellum in RE. ${ }^{3,-9}$ Despite these reports of both typical contralesional and atypical ipsilesional cerebellar atrophy, the cerebellum has never been systematically analyzed in a large patient cohort. Thus, the present study aimed to quantify volumetric changes of the cerebellar gray matter (GM) and white matter (WM) in a representatively large cohort of patients with RE. Furthermore, our analysis is complemented by fiber tractography and the assessment of cerebellar fluid-attenuated inversion recovery (FLAIR) image hyperintensities indicative of inflammatory processes.

\section{Methods}

\section{Study Group}

In the present work, we retrospectively analyzed an RE cohort of all 57 patients (37 women, 33 left foci, mean age \pm SD: $21.6 \pm$ 15.7 years) who were treated at the Department of Epileptology of the University Hospital Bonn between 2001 and 2019 (Table 1). All of them met the formal RE diagnosis criteria. ${ }^{1}$ In addition, at least 1 preoperative, structural T1-weighted MRI scan had to be available. To capture the most advanced alterations within the chronic stage of RE, the latest available scan of each patient (before hemispherotomy, if applicable) was selected for analysis. Following previously described disease stages, ${ }^{10}$ we separately analyzed patients in a more acute and more chronic stage with an onset scan interval of less than 4 (n $=17)$ and 4 or more years $(n=39)$, respectively. All patients had epileptic seizures, 7 of them experienced 1 or more status epilepticus in the past. Forty-seven of the 57 patients had received immunosuppressive medication (including glucocorticoids, tacrolimus, mycophenolate mofetil, and azathioprine), and all patients, except 2 , took antiseizure medication (various, phenytoin in 12 cases). There were no patients with a clinically diagnosed bilateral variant of RE, neither at the time of the MRI nor later in their disease course. In 13 cases, hemispherotomy was performed. In addition, scans of 57 age- and sex-matched controls (CON) with normal MRI (CON; 37 women, mean age \pm SD: $21.6 \pm 15.9$ years; Table 1$)$ were retrospectively ascertained at the University Hospital Bonn, in an existing inhouse database of Charité Universitätsmedizin Berlin, and as part of the Human Connectome Project. ${ }^{11}$ For 13 patients, additionally available diffusion tensor imaging (DTI) data sets were assessed. Please see Table 1 for summarized demographic information and eTable 1, links.lww.com/NXI/A546, for individual demographic information.

\section{MRI Data Sets}

MRI data sets of all 57 patients were collected at the Department of Epileptology, the Department of Radiology, and the Department of Neuroradiology of the University Hospital Bonn. Volumes were acquired at both $3 \mathrm{~T}(\mathrm{n}=46)$ and $1.5 \mathrm{~T}(\mathrm{n}=11)$ field strength using either a 32-channel or an 8-channel head coil. MRI data sets of $28 \mathrm{CON}$ were acquired at a 3T Siemens scanner (Siemens Healthineers, Erlangen, Germany) at the Department of Epileptology of the University Hospital Bonn using a 32-channel head coil. MRI volumes of $29 \mathrm{CON}$ were externally acquired at a 3T Siemens scanner (Siemens Healthineers, Erlangen, Germany) at the Charité Universitätsmedizin Berlin using a 64-channel head coil $(\mathrm{n}=18)$ and, as part of the Human Connectome Project, from the Washington University-University of Minnesota Consortium using a 32-channel head coil $(\mathrm{n}=11)$. All 3D T1weighted data sets have an isotropic voxel size $\leq 1.1 \mathrm{~mm}$. FLAIR data sets included both $2 \mathrm{D}$ coronary and $3 \mathrm{D}$ protocols. In 4 patients with no FLAIR data sets available, T2-weighted sequences were used. DTI scans of 7 patients were acquired with 60 diffusion gradient directions and a b-value $=1,000 \mathrm{~s} / \mathrm{mm}^{2}$. Six DTI data sets were acquired with 32 diffusion gradient directions and a b-value $=1,000 \mathrm{~s} / \mathrm{mm}^{2}(\mathrm{n}=5)$ or b-value $=800 \mathrm{~s} / \mathrm{mm}^{2}(\mathrm{n}=$ 1). Please see eAppendix 1 , links.lww.com/NXI/A560, for further detail on acquisition parameters.

\section{Voxel-Based Morphometry}

To enable statistical comparison, scans of patients with RE exhibiting a right hemispheric disease focus (and matched CON) were flipped along the $\mathrm{x}$-axis. Preprocessing of T1weighted scans was conducted using the spatially unbiased infratentorial atlas template (SUIT) toolbox implemented in 
Table 1 Demographic and Clinical Information of Patients and CON

\begin{tabular}{|c|c|c|c|c|c|c|c|c|c|}
\hline & \multicolumn{3}{|c|}{ Demographics } & \multicolumn{2}{|l|}{ MRI } & \multicolumn{4}{|l|}{ Treatment } \\
\hline & $\operatorname{Sex}(F)$ & IL (left) & $\begin{array}{l}\text { Age at onset } \\
\text { (y; M [IQR]) }\end{array}$ & $\begin{array}{l}\text { Age at scan } \\
\text { (y; M [IQR]) }\end{array}$ & DTI & $\begin{array}{l}\text { No. of ASM }{ }^{a} \\
\text { (M [IQR]) }\end{array}$ & $\mathrm{PHT}^{\mathrm{b}}$ & Cort $^{c}$ & HE \\
\hline $\operatorname{RE}(n=57)$ & 37 & 33 & $8(5-17)$ & $17(9-29)$ & 13 & $6(4-9)$ & 12 & 10 & 13 \\
\hline RE acute $(n=17)$ & 14 & 12 & $6(5-9)$ & $8(6-12)$ & 4 & $5(3-6)$ & 1 & 3 & 6 \\
\hline RE chronic $(n=39)$ & 23 & 20 & $9(6-20)$ & $20(15-37)$ & 9 & $6(5-10)$ & 11 & 7 & 7 \\
\hline RE positive AI $(n=30)$ & 21 & 17 & $9(6-14)$ & $18(12-29)$ & 6 & $6(5-10)$ & 8 & 6 & 8 \\
\hline RE negative Al $(n=27)$ & 16 & 16 & $8(5-22)$ & $15(8-31)$ & 7 & $5(3-7)$ & 4 & 4 & 5 \\
\hline $\operatorname{CON}(n=57)$ & 37 & - & - & $17(9-29)$ & - & - & - & - & - \\
\hline
\end{tabular}

Abbreviations: $\mathrm{Al}=$ asymmetry index; $\mathrm{ASM}=$ antiseizure medication; $\mathrm{CON}=$ controls; Cort = cortisone; $\mathrm{DTI}=$ diffusion tensor imaging; $\mathrm{F}=$ female; $\mathrm{HE}=$ hemispherotomy; IL = ipsilesional hemisphere; IQR = interquartile range; $\mathrm{M}=$ median; $\mathrm{PHT}=$ phenytoin; RE = patients with Rasmussen encephalitis.

${ }^{a}$ Cumulative number of ASMs in the patient's history.

b Use of phenytoin in the patient's history.

'Use of cortisone at the time of MRI acquisition.

the Statistical Parametric Mapping (SPM12) framework. ${ }^{12}$ All volumes were brought into an orientation where negative numbers are to the left, posterior, and inferior (LPI), and the origin of each image was set to the anterior commissure. Processing steps included isolation of the cerebellum, tissue-type segmentation, and spatial normalization of the gray and WM segmentations onto the SUIT atlas template using DARTEL. ${ }^{13}$ Generated Jacobian maps, mathematically describing local expansion or shrinkage during nonlinear tissue registrations, were used for voxel-based morphometry (VBM) statistical analysis. A group comparison was implemented using a voxel-wise general linear model. Nonparametric permutation tests with 5,000 iterations were performed to account for multiple comparisons by family-wise error (FWE) correction using the threshold-free cluster enhancement procedure. ${ }^{14}$ This procedure was repeated adjusting for different scanners and the simultaneous use of cortisone at the time of the scan.

\section{Calculation of Asymmetry Indices}

Inspired by the well-established cerebral hemispheric ratio, ${ }^{10,15}$ we calculated asymmetry indices (AIs) of cerebellar hemispheres providing a relative, observer-independent measure for the evaluation of cerebellar abnormalities at a single patient level. Based on generated Jacobian maps of structural T1-weighted sequences, morphometric AIs were used for the assessment of cerebellar atrophy and calculated according to the following equation:

$$
\text { Morphometric AI }=\frac{2\left(\mu_{j a c}^{I L}-\mu_{j a c}^{C L}\right)}{\mu_{j a c}^{L L}+\mu_{j a c}^{C L}}
$$

where $\mu_{j a c}^{I L}$ and $\mu_{j a c}^{C L}$ is the mean of the GM Jacobian determinant map of the ipsilesional and contralesional cerebellar hemisphere, respectively.

Positive morphometric AI scores indicate a greater volume loss in the contralesional cerebellum, whereas negative morphometric AIs indicate a greater ipsilesional volume loss. To compare the variance between morphometric AIs of patients and $\mathrm{CON}$, a 2-sample unpaired $F$ test was performed. Morphometric AIs of patients with and without phenytoin were compared using a 2 -sample unpaired $t$ test.

Based on WM segmentations of FLAIR sequences, FLAIR intensity AIs were used for the assessment of cerebellar inflammation and calculated according to the following equation:

$$
\text { FLAIR intensity AI }=\frac{2\left(\mu_{\text {int }}^{\mathrm{CL}}-\mu_{\text {int }}^{\mathrm{IL}}\right)}{\mu_{\mathrm{int}}^{\mathrm{IL}}+\mu_{\mathrm{int}}^{\mathrm{CL}}}
$$

where $\mu_{\text {int }}^{I L}$ and $\mu_{\text {int }}^{C L}$ is the mean intensity of the ipsilesional and contralesional cerebellar WM, respectively.

Positive FLAIR intensity AI scores indicate a higher intensity in the contralesional cerebellar WM, whereas negative FLAIR intensity AIs indicate a higher ipsilesional intensity.

The Pearson correlation coefficient was used to describe the association between morphometric AIs and age at disease onset and between morphometric AI scores and FLAIR intensity AI scores. Correlations of morphometric AIs and FLAIR intensity AIs between patients with greater contralesional and with greater ipsilesional cerebellar volume loss were statistically compared using a 2-sided Fisher z-test. To account for inhomogeneous scanner protocols, we compared AIs of the subsets of patients with different $\mathrm{T} 2$-weighted sequences using a one-way analysis of variance.

\section{Fiber Tractography}

DTI images were processed using a combination of the FMRIB Software Library $6.0^{16}$ (FSL) and the MRtrix 3 package. ${ }^{17}$ Volumes were corrected for susceptibility-induced geometric distortions by generating a synthesized $\mathrm{b} 0^{18}$ and applying the FSL tool topup. ${ }^{19}$ Artifacts caused by motion and eddy currents were corrected by applying the FSL tool eddy. ${ }^{20}$ 
Next, fractional anisotropy (FA) was calculated for each voxel by fitting a diffusion tensor model. Constrained spherical deconvolution was used to estimate the voxel-wise fiber orientation distributions (FODs). ${ }^{21}$ Based on the FODs, we performed whole-brain anatomically constrained tractography generating 10 million streamlines. ${ }^{22}$ Filtering of implausible streamlines was performed using Spherical-deconvolution Informed Filtering of Tractograms. ${ }^{23}$ The CPC tract was reconstructed along 2 hand-drawn ROIs in the cerebellar peduncle and the contralateral cerebral peduncle, as described elsewhere. ${ }^{24}$ For exclusion of potential non-CPC fibers, exclusion masks were placed in the contralateral cerebellar peduncle, in the medulla oblongata, and within the corpus callosum. Last, FA of the crossing CPC tracts was compared using a 2 -sample paired $t$ test.

\section{Independent Component Analysis}

We conducted an independent component analysis (ICA) on the preprocessed Jacobian maps to separate spatial patterns of GM differences in patients with RE. Here, following the sourcebased morphometry approach, Jacobian maps of the individual subjects are decomposed into a linear combination of mutually independent patterns and their respective normalized loading coefficient. ${ }^{25}$ ICA was performed on the complete data set of patients and CON using the Group ICA of functional MRI toolbox with the number of estimated components set to 30 following ICASSO stabilization. Artifactual components were filtered out visually. Loading coefficients between groups were compared using a 2-sample unpaired $t$ test and corrected for multiple comparisons using the false discovery rate (FDR).

\section{Standard Protocol Approvals, Registrations, and Patient Consents}

The study was approved by the University Hospital Bonn Institutional Review Board and by the Institutional Review Board of Charité Universitätsmedizin Berlin. Written informed consent was obtained from all patients and CON.

\section{Data Availability}

The data that support the findings of this study are available on reasonable request from the corresponding author. Data are not publicly available as they contain information that could comprise the privacy of patients and research participants.

\section{Results}

\section{Volumetric Analysis}

The group comparison between $\mathrm{CON}$ and patients with $\mathrm{RE}$ resulted in a widespread, bihemispheric cluster indicating lower cerebellar GM volume in patients with RE (FWE-corr. $p<0.01$; Figure 1A). Dissimilarities were more pronounced in the contralesional hemisphere, especially in the lateral part of the crus I and II and in the lobules VII, VIII, and IX. VBM analysis additionally adjusted for different scanners and the use of cortisone at the time of data acquisition resulted in comparable clusters of lower cerebellar GM volume in patients with RE than in CON (FWE-corr. $p<0.01$; eFigure 1,
links.lww.com/NXI/A544). Both patients in a more acute and in a more chronic stage showed bilaterally decreased cerebellar GM volume compared with CON (FWE-corr. $p<$ $0.05)$. Although in the former, clusters were located in the anterior lobe of the cerebellum, GM volume differences in the more chronic group were found in the posterior cerebellar lobe (Figure 1B). VBM of the WM of the cerebellum and the brain stem demonstrated significantly lower WM volume in patients with RE CON, most pronounced within the ipsilesional mesencephalon and bilateral cerebellar peduncles (FWE-corr. $p<0.01$; Figure 1C).

\section{Als}

Morphometric AIs, as depicted in Figure 2A, revealed significantly higher variance within the $\mathrm{RE}$ group than within $\mathrm{CON}$ $(F=11.093, p<0.001)$. In 30 patients, we observed positive morphometric AI scores, corresponding to a lower contralesional GM volume, whereas in 27 patients, negative morphometric AI scores, indicative of a lower ipsilesional GM volume, were observed. Absolute morphometric AIs of patients predominantly showing a lower ipsilesional cerebellar GM volume correlated with age at onset $(r=0.61, p<0.001)$ : The higher the age at onset, the lower the relative GM volume of the ipsilesional hemisphere. In contrast, in patients with predominant lower contralesional cerebellar GM volume $(n=30)$, we did not observe a correlation between morphometric AIs and age at disease onset $(r=-0.02, p=0.910)$. Morphometric AIs of patients who had taken phenytoin did not significantly differ from AIs of patients without $(p=0.92)$.

Correlations between FLAIR intensity AIs and morphometric AIs significantly differed between patients with predominantly contralesional and predominantly ipsilesional cerebellar atrophy $(\mathrm{z}=2.70, p<0.01$; Figure 2B). FLAIR intensity AIs of patients with predominantly contralesional cerebellar atrophy weakly correlated with morphometric AI scores $(r=0.49, p<$ 0.001). FLAIR intensity AIs of patients with predominantly ipsilesional cerebellar atrophy showed a strong correlation with morphometric AI scores $(r=0.86, p<0.001)$. We did not find a significant effect of scanner protocol in AIs of patients with different T2-weighted sequences $(F=0.29, p=0.75$; eFigure 2, links.lww.com/NXI/A545).

\section{Side Comparison of the CPC Tracts}

$\mathrm{CPC}$ tracts connecting the ipsilesional cerebrum with the contralesional cerebellum showed significantly lower FA than the mirrored CPC tracts $(T=2.30, p<0.05$; Figure $3 \mathrm{~A})$. However, interindividual differences were observed. Tracts in an exemplary patient, weighted by their local FA, are displayed in Figure 3B.

\section{Group Differences in ICA Patterns}

The full data set was decomposed in 30 components. Of these, 5 components were excluded as artifacts due to their spatial distribution along the edges of the cerebellum or within WM regions. Of the remaining components, 8 patterns showed a significant difference in their loading coefficients between patients with RE and CON, all of them including cerebellar regions 


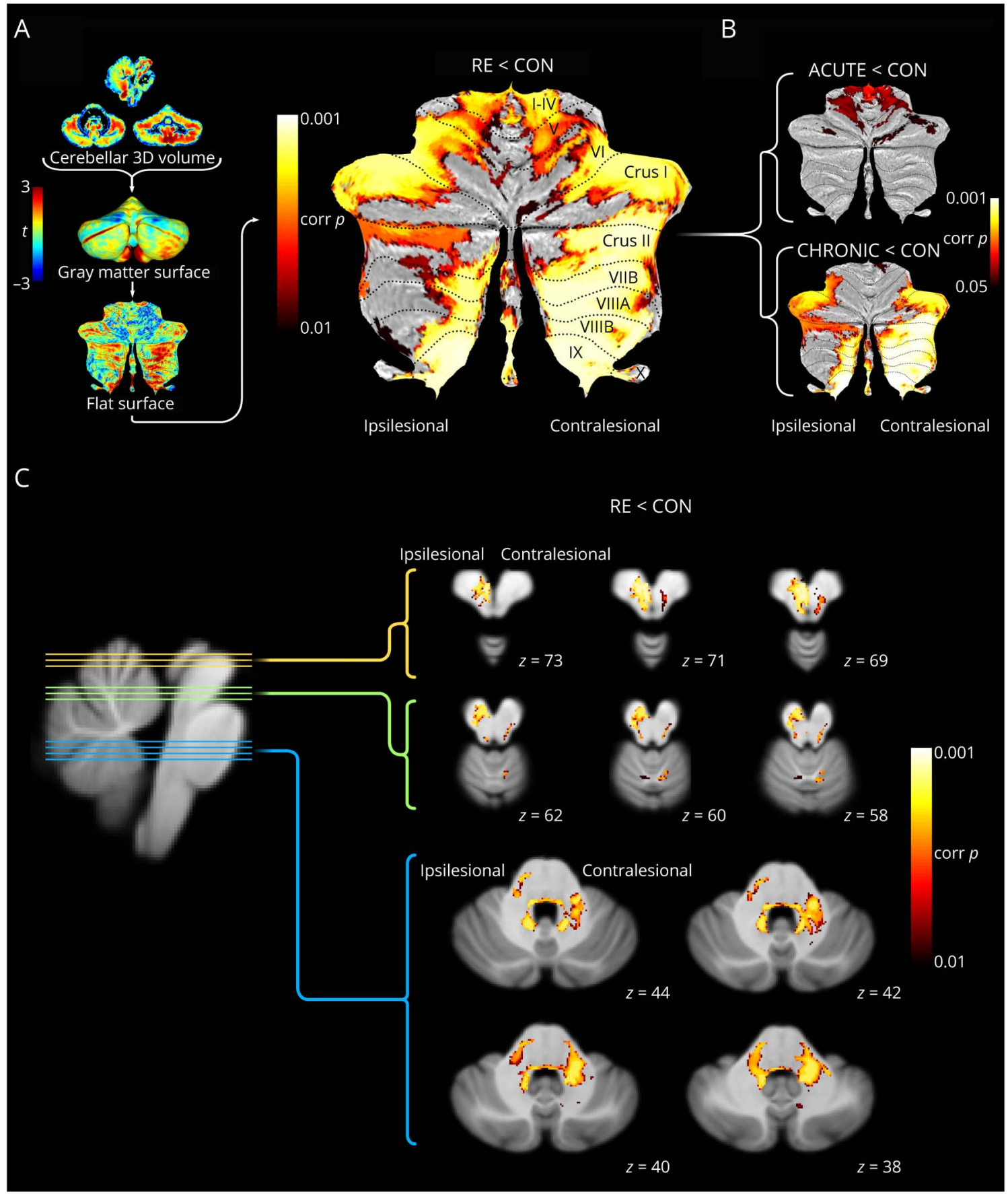

(A) Mapping of results from 3-dimensional voxel-wise statistics onto a flattened cerebellar surface reveals widespread bilateral clusters of lower cerebellar gray matter volume in patients with RE compared with CON. Jet colormap indicates raw $t$ values. Hot colormap indicates FWE-corrected $p$ values. (B) Projections on the flatmap show bilaterally lower cerebellar gray matter volume in both more acute (ACUTE) and more chronic (CHRONIC) patients with RE compared with CON. (C) White matter differences between patients with RE and CON. Hot colors indicate FWE-corrected $p$ values. $z$ indicates $z$ coordinate in Montreal Neurological Institute and Hospital space. CON = controls; FWE = family-wise error; RE = Rasmussen encephalitis.

of decreased GM volume in patients with RE (FDR-corr $p<$ 0.05 , Figure 4). Components $1,3,22$, and 26 describe bilateral patterns of atrophy covering large parts of the cerebellum. Components 9 and 23 cover strictly contralesional cerebellar regions, such as lobules V, VI, VIII, and IX. In contrast, components 15 and 28 include strictly ipsilesional regions, namely the medial and lateral parts of lobules VII, VII, and IX.

\section{Discussion}

This study was driven by the hypothesis that brain abnormalities in RE are not restricted to the cerebrum, but can also be found in the cerebellum and brainstem. We further hypothesized that these differences to healthy brains are not solely explainable by secondary atrophy, but are likely to 


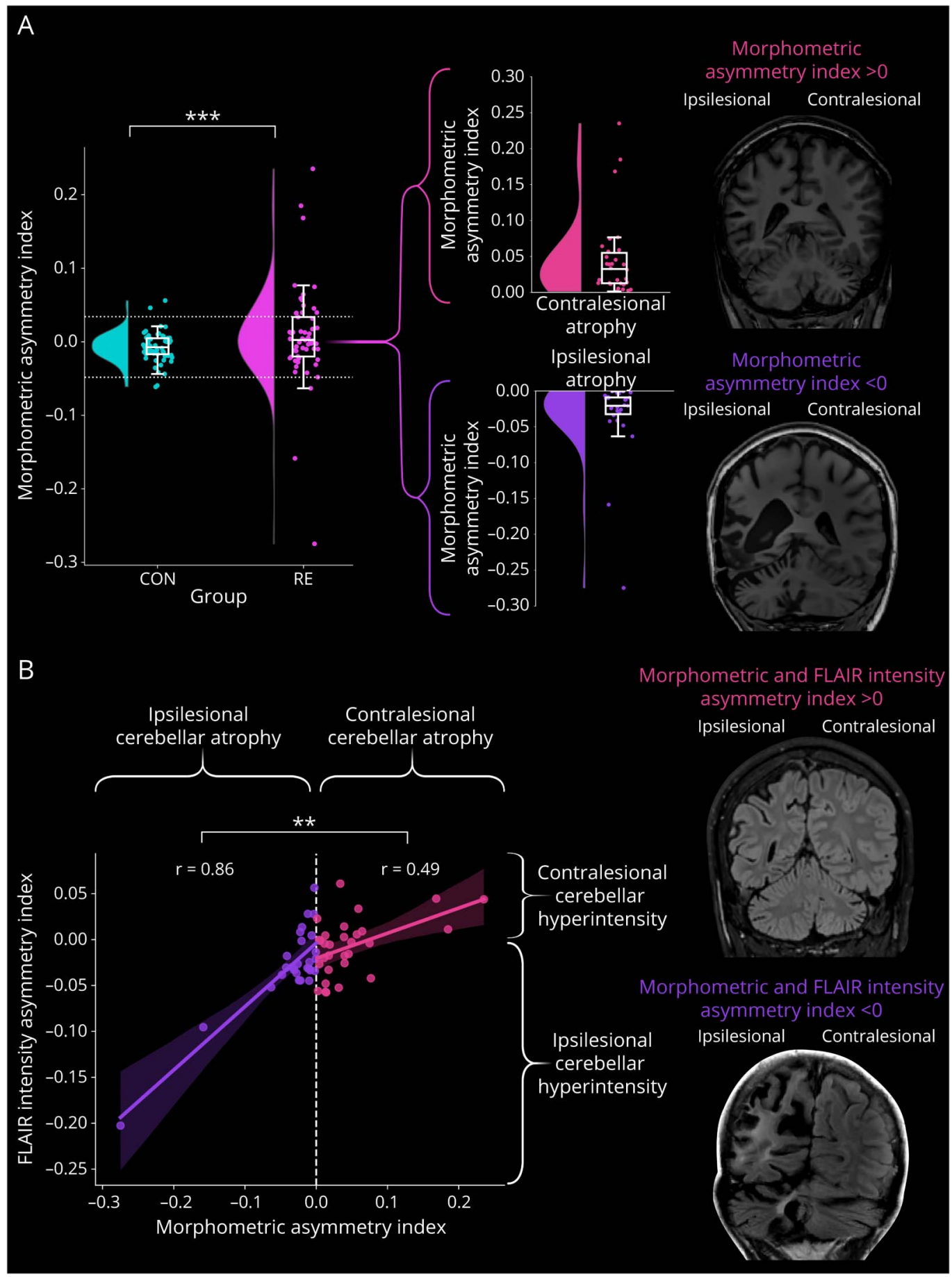

(A) Morphometric Als of cerebellar hemispheres show a greater variance in patients with RE than in CON $(F=11.093$, *** $p<0.001$; dotted horizontal lines indicate double SD of morphometric Als of control). Thirty patients showed positive Als, whereas 27 showed negative asymmetry values. MR images show 2 representative cases of the predominantly ipsilesional and contralesional atrophy patterns. (B) Correlation of FLAIR intensity Als and morphometric Als significantly differed in patients with predominantly ipsilesional and contralesional cerebellar atrophy $(z=2.70, * * p<0.01)$. A strong correlation between Als was found in patients with predominantly ipsilesional cerebellar atrophy $(r=0.86, p<0.001)$. MR images show 2 representative cases of predominantly ipsilesional and contralesional atrophy patterns. Als = asymmetry indices; CON = controls; FLAIR = fluid-attenuated inversion recovery.

follow an inflammation in the scope of a primary involvement of the cerebellum by RE. The volumetric grouplevel analysis yields widespread atrophy within both the ipsilesional and the contralesional cerebellar hemispheres in patients with RE, both in the acute and chronic disease stages. Decomposition of the data identified 3 different patterns of cerebellar atrophy:

Patients with a morphometric AI close to 0 did not show large differences in the volume of ipsi- and contralesional cerebellar 


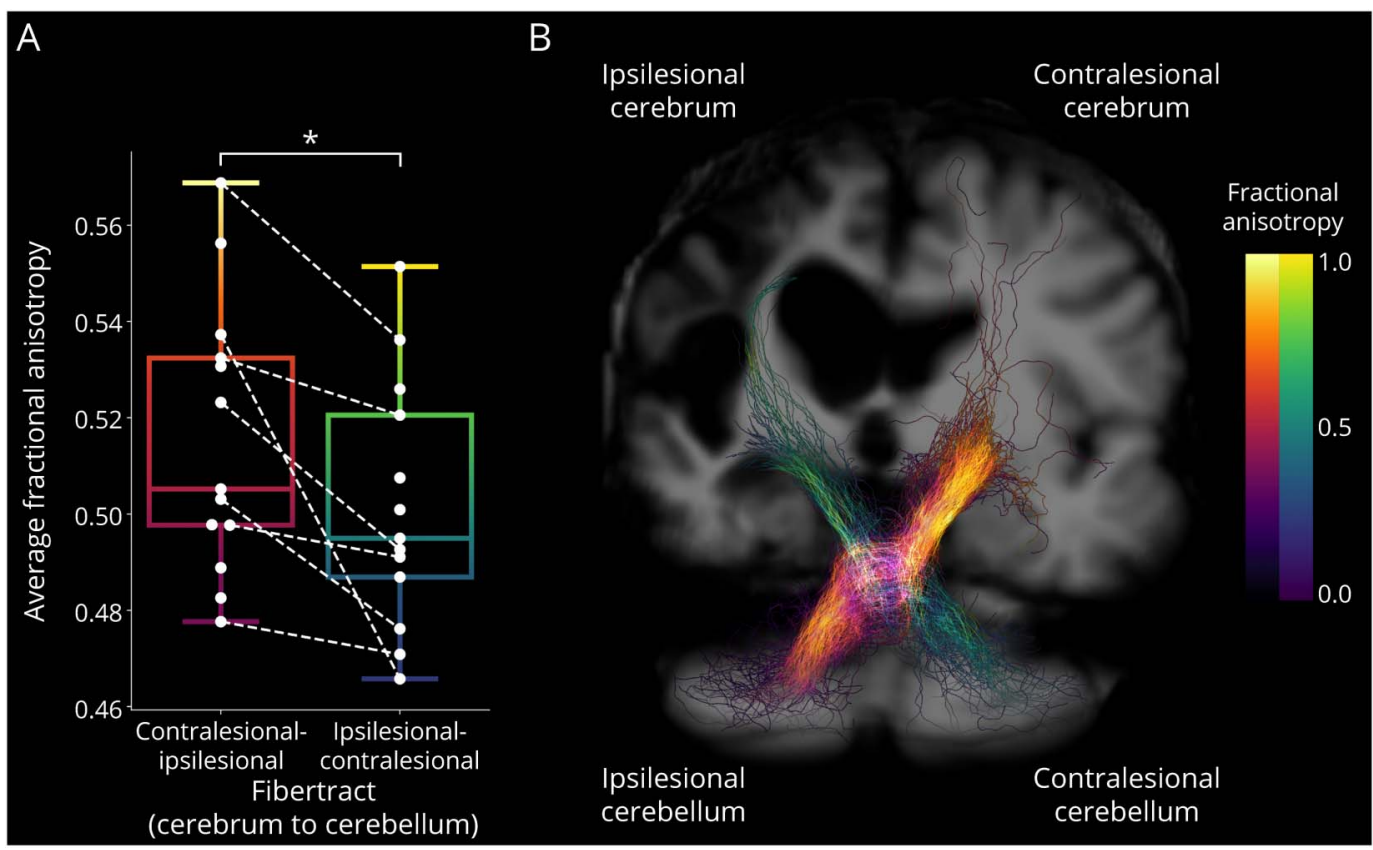

(A) Mean FA of CPC fiber tracts connecting the ipsilesional cerebrum with the contralesional cerebellum showed significantly lower values than opposite tracts $\left({ }^{\star} p<0.05\right)$. Dashed lines indicate individual tract pairs where voxel-wise FA values between tracts differed significantly $\left(2\right.$-sample unpaired $t$ test, $\left.{ }^{\star} p<0.05\right)$. (B) Exemplary CPC fiber tracts of 1 patient weighted according to the corresponding local FA values. CPC = cortico-ponto-cerebellar; FA = fractional anisotropy.

hemispheres. Similarly, most components determined through ICA showed a bilateral spatial distribution. Firstly, this pattern of cerebellar atrophy may be a consequence of epileptic discharges, as it has been shown in other epileptic conditions, especially chronic temporal lobe epilepsy. ${ }^{26,27}$ In our study, the influence of recurrent seizures on bilateral cerebellar atrophy is supported by the stronger atrophy observed in chronically affected patients. Of interest, anterior and posterior lobes were oppositely affected in acute and chronic patients, with the anterior lobe being spared in the chronic subsample. This is in line with a previous study investigating patients with chronic temporal lobe epilepsy, which reported bilateral cerebellar atrophy only in posterior lobes, whereas anterior lobes, surprisingly, showed even higher volumes compared with $\mathrm{CON}^{26}$ According to the inhibitory influence of the anterior lobe on the thalamus, they discussed the possibility of a compensatory volume gain in response to chronic seizures. ${ }^{26}$ The question of whether similar mechanisms counterpoise atrophy in anterior lobes of chronic patients with RE is highly speculative and would be better answered in longitudinal studies. Second, adverse effects of antiseizure medications, particularly phenytoin, may have resulted in bilateral, symmetric cerebellar atrophy. ${ }^{27}$ However, only 12 of 57 patients received phenytoin in our cohort. Thus, the influence of this drug on measured atrophy is negligible. Furthermore, the application of immunosuppressive medication, especially of cortisone, may have influenced cerebellar volume. ${ }^{28}$ However, adjustment of our VBM for cortisone at the time of the scan produced comparable clusters of bilateral cerebellar atrophy. Last, decomposition of the volumetric data suggests that different atrophy processes specifically affecting the ipsilesional or contralesional cerebellum could have occurred in combination and, therefore, manifested as symmetric atrophy with a morphometric AI close to 0 . This, in turn, could be the reason for the observed normal distribution of positive and negative morphometric AIs centered around 0 . Taken together, the so far described factors may have contributed to the bilateral, surprisingly symmetric atrophy in our study. However, they equally fail to explain the strong asymmetric cerebellar atrophy measured in some patients.

Asymmetric cerebellar atrophy with a lower volume in the contralesional cerebellar hemisphere has been reported occasionally in RE and attributed to crossed cerebellar atrophy. ${ }^{3,4,29}$ The extent of the supratentorial lesion and the preexistence of status epilepticus have been shown to play a major role in the evolution of this condition in patients with epilepsy with destructive brain insult early in life. ${ }^{5}$ In the investigated cohort of patients with RE, both factors were also present and might have caused damage to the crossing CPC pathway. In our volumetric group-level analysis, atrophy in the WM occurred bilaterally in the cerebellum and almost exclusively ipsilesional in the mesencephalon. In line with the expected atrophy caused by crossed cerebellar atrophy, clusters of lower volume followed the anatomic course of the ipsilesional-to-contralesional CPC tract, sparing the contralesional mesencephalon. The differences found in FA between the 2 CPC tracts also indicate damage to the ipsilesional-to-contralesional tract and corroborate crossed cerebellar atrophy as the explanation for asymmetric 


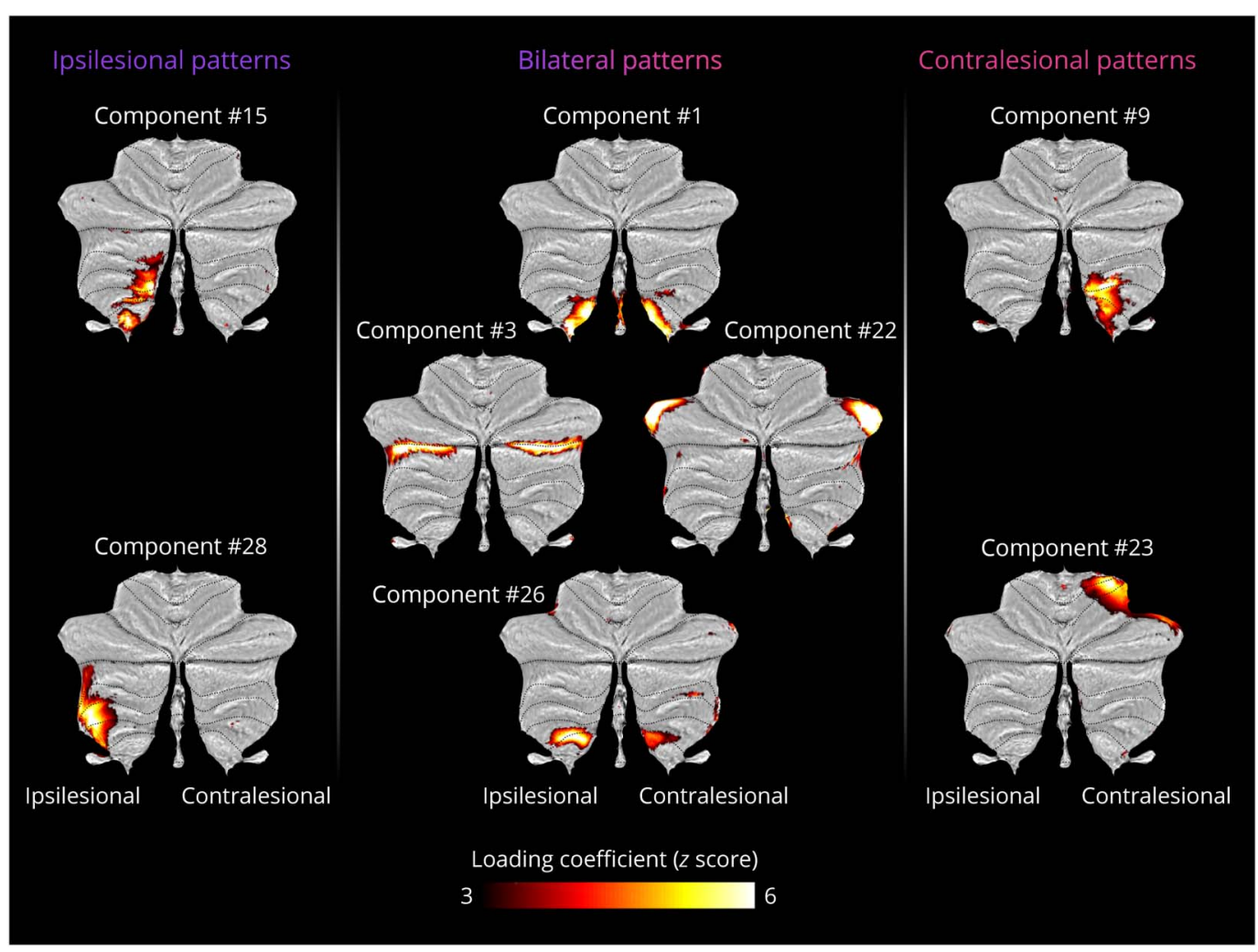

Eight of 30 components showed a significant difference in their loading coefficients between patients with RE and CON (FDR-corr $p<0.05)$ and indicated decreased GM volume in patients. ICA results are distinguishable in bilateral, strictly contralesional, and strictly ipsilesional patterns. A threshold of $z>3$ was applied to all spatial component maps. Colormap indicates the normalized loading coefficients. CON = controls; FDR = false discovery rate; ICA = independent component analysis; RE = Rasmussen encephalitis.

contralesional cerebellar atrophy. This finding calls to mind the presence and potential extent of secondary atrophy following Wallerian degeneration, which extends beyond the original, focal lesion and may involve distant regions as both the contralesional cerebellum and the contralesional cerebrum.

The processes behind the lower volume in both the ipsilesional cerebellar GM and WM at the group level, the ipsilesional components resulting from the ICA, and the strongly asymmetric ipsilesional cerebellar atrophy in individual patients are more enigmatic. Cerebellar atrophy, ipsilesional to the cerebral focus, has been reported anecdotally before; however, the reason for this remained unknown. ${ }^{3,6-9}$ In this study, particularly strong correlations of FLAIR intensity AIs, indicative of possible asymmetrical inflammatory processes in the cerebellum, and morphometric AIs can be found for patients with predominantly ipsilesional cerebellar atrophy. Hyperintensities in FLAIR images of patients with ipsilesional cerebellar atrophy, correlating with the severity of volumetric damage, strongly promote that the inflammation in $\mathrm{RE}$ is not restricted to the cerebrum but can further spread in the brainstem and even enter the ipsilesional cerebellum. A primary cerebellar inflammation in a patient diagnosed with RE has not been reported so far, but an involvement of the ipsilesional brainstem has been. ${ }^{7}$ Moreover, in a 1984 report, the authors presented an autopsied patient who died at age 7 , which retrospectively allowed the diagnosis of RE (case 5).$^{30}$ Of interest, the brain autopsy of this patient not only showed atrophy and inflammation in the cerebrum but also revealed ipsilesional cerebellar atrophy and inflammation within the ipsilesional brainstem and cerebellum. ${ }^{30}$ Furthermore, a recent study on unilateral relapsing primary angiitis of the CNS, which shares RE's characteristical unilateral brain involvement, discussed the possibility that both conditions might be related and could lie in the same disease spectrum. ${ }^{31}$ Of interest, an ipsilesional cerebellar or brainstem involvement was also found in 2 of 3 patients. ${ }^{31}$ In our data set, age at disease onset and morphometric AIs only correlated in patients with predominant ipsilesional cerebellar atrophy in the sense that a later disease onset was associated with a stronger asymmetry. This is noteworthy, as published patients with $\mathrm{RE}$ showing ipsilesional cerebellar atrophy are associated with a concomitant, uncommon occipital disease focus, which in turn has also been associated with later disease onset. ${ }^{6,9,32}$ Taken together, our findings support the hypothesized primary cerebellar inflammation explaining both the here quantitatively assessed and the previously reported ipsilesional cerebellar atrophy in RE. ${ }^{3,6-9}$ This may suggest an elevated risk of motor and nonmotor cerebellar functional abnormalities in patients with $\mathrm{RE}$, which, in the future, need to be systematically assessed, for example, by using the scale for the assessment and rating of 
ataxia (SARA) score and the cerebellar cognitive affective syndrome (CCAS)/Schmahmann scale, respectively. ${ }^{33,34}$

This study morphometrically investigated the cerebellum in a large cohort of patients with RE. Although its results ground our suspicion of a primarily affected cerebellum, they remain fragmentary for the most obvious limitation - the inclusion of brain imaging data where brain biopsies and histologic analysis would be needed to ultimately claim inflammation in the cerebellum of patients with RE. The association between imaging markers and their structural underpinnings remains overly simplistic, and cerebellar brain biopsies are not available for evident reasons. These hurdles cannot be overcome by our study. Another limitation of this study are the inhomogeneous MRI acquisition protocols. However, although AIs and tract comparisons calculated in this study are within-subject measures and therefore unlikely to contain scanner-specific biases, the ICA approach we used was previously shown to robustly eliminate scannerspecific artifacts. ${ }^{35}$ Beyond that, the remaining VBM analysis did show comparable results when adjusting for different scanners and the use of $3 \mathrm{D}$ or $\mathrm{T} 2$-weighted data sets did not have a significant influence on the FLAIR intensity AIs. Last, despite our comparably large sample size, it has to be noted that our patient cohort stems from a single epilepsy center and possible sampling biases cannot be completely ruled out. Furthermore, tractography results lack statistical power due to a reduced number of patients providing diffusion data and should, therefore, be taken with caution.

Taken together, our analyses were both challenged by and indicative for the varying manifestations of the same disease. Thus, a crucial factor for a better understanding of RE might be the differentiation of possible disease subgroups showing distinct cerebral and cerebellar atrophy patterns. ${ }^{36}$ Together with recent studies showing seemingly contradictory volumetric changes on the contralesional cerebral hemisphere, ${ }^{37,38}$ the present work identified different patterns of cerebellar atrophy, suggests an ipsilesional cerebellar inflammation, and complements the picture of complex brain alterations in patients with $\mathrm{RE}$, extending beyond the affected hemisphere.

\section{Acknowledgment}

J. Reiter has received funding from EKFS Doctoral Program NeuroImmunology of the medical faculty of the University of Bonn (2020-S2-01). B. David and J. Reiter are recipients of scholarships from the Bischöfliche Studienförderung Cusanuswerk. Data were provided (in part) by the Human Connectome Project, WU-Minn Consortium (Principal Investigators: David Van Essen and Kamil Ugurbil; 1U54MH091657) funded by the $16 \mathrm{NIH}$ Institutes and Centers that support the NIH Blueprint for Neuroscience Research and by the McDonnell Center for Systems Neuroscience at Washington University. Research by A.M. Kaindl is funded by the German Research Foundation (DFG; SFB1315, FOR3004). The authors thank Dr. Christian Bien (Bielefeld University, Department of Epileptology [Krankenhaus Mara]) for the critical revision of the manuscript.

\section{Study Funding}

No targeted funding reported.

\section{Disclosure}

The authors report no disclosures relevant to the manuscript. Go to Neurology.org/NN for full disclosures.

\section{Publication History}

Received by Neurology: Neuroimmunology \& Neuroinflammation March 25, 2021. Accepted in final form June 29, 2021.

\section{Appendix Authors}

\begin{tabular}{lll}
\hline Name & Location & Contribution \\
\hline $\begin{array}{l}\text { Johannes } \\
\text { T. Reiter }\end{array}$ & $\begin{array}{l}\text { Department of Epileptology, } \\
\text { University Hospital Bonn, } \\
\text { Germany }\end{array}$ & $\begin{array}{l}\text { Data acquisition, major role in } \\
\text { data and statistical analysis, } \\
\text { study design, and drafted and } \\
\text { revised the manuscript }\end{array}$ \\
\hline
\end{tabular}

Bastian Department of Epileptology, Data acquisition, major role in

David, MSc University Hospital Bonn, data and statistical analysis, Germany study design, and drafted and revised the manuscript

\begin{tabular}{lll}
\hline $\begin{array}{l}\text { Selma } \\
\text { Enders, } \\
\text { MSc }\end{array}$ & $\begin{array}{l}\text { Department of Epileptology, } \\
\text { University Hospital Bonn, } \\
\text { Germany }\end{array}$ & $\begin{array}{l}\text { Data acquisition and revision } \\
\text { of the manuscript for } \\
\text { intellectual content }\end{array}$ \\
\hline $\begin{array}{l}\text { Conrad } \\
\text { Prillwitz, } \\
\text { MD }\end{array}$ & $\begin{array}{l}\text { Department of Epileptology, } \\
\text { University Hospital Bonn, } \\
\text { Germany }\end{array}$ & $\begin{array}{l}\text { Data acquisition and revision } \\
\text { of the manuscript for } \\
\text { intellectual content }\end{array}$ \\
\hline $\begin{array}{l}\text { Tobias } \\
\text { Bauer, BSc }\end{array}$ & $\begin{array}{l}\text { Department of Epileptology, } \\
\text { University Hospital Bonn, }\end{array}$ & $\begin{array}{l}\text { Data acquisition and revision } \\
\text { of the manuscript for } \\
\text { intellectual content }\end{array}$ \\
\hline $\begin{array}{l}\text { Germany } \\
\text { Deniz }\end{array}$ & $\begin{array}{l}\text { Charité - Universitätsmedizin } \\
\text { Berlin, Department of }\end{array}$ & $\begin{array}{l}\text { Data acquisition and revision } \\
\text { of the manuscript for } \\
\text { intellectual content }\end{array}$ \\
& $\begin{array}{l}\text { Pediatric Neurology, Berlin, } \\
\text { Germany; Charité - }\end{array}$ & \\
& $\begin{array}{l}\text { Universitätsmedizin Berlin, } \\
\text { Center for Chronically Sick } \\
\text { Children, Berlin, Germany }\end{array}$ &
\end{tabular}

\begin{tabular}{lll}
\hline $\begin{array}{l}\text { Anna } \\
\text { Tietze, MD, } \\
\text { PhD }\end{array}$ & $\begin{array}{l}\text { Charité-Universitätsmedizin } \\
\text { Berlin, Institute of } \\
\text { Neuroradiology, Germany }\end{array}$ & $\begin{array}{l}\text { Data acquisition and revision } \\
\text { of the manuscript for } \\
\text { intellectual content }\end{array}$ \\
\hline $\begin{array}{l}\text { Angela M. } \\
\text { Kaindl, } \\
\text { MD, PhD }\end{array}$ & $\begin{array}{l}\text { Charité - Universitätsmedizin } \\
\text { Berlin, Department of }\end{array}$ & $\begin{array}{l}\text { Data acquisition and revision } \\
\text { of the manuscript for } \\
\text { intellectual content }\end{array}$ \\
& $\begin{array}{l}\text { Germany; } \\
\text { Charité-Universitätsmedizin }\end{array}$ & \\
& $\begin{array}{l}\text { Berlin, Center for Chronically } \\
\text { Sick Children, Germany; }\end{array}$ & \\
& Charité-Universitätsmedizin & \\
& Berlin, Institute for Cell & \\
& Biology and Neurobiology, \\
& Germany
\end{tabular}

\begin{tabular}{lll}
\hline $\begin{array}{l}\text { Vera Keil, } \\
\text { MD }\end{array}$ & $\begin{array}{l}\text { Department of } \\
\text { Neuroradiology, University } \\
\text { Hospital Bonn, Bonn, } \\
\text { Germany; Department of } \\
\text { Radiology and Nuclear } \\
\text { Medicine, Vrije Universiteit } \\
\text { Amsterdam Medisch } \\
\text { Centrum, Amsterdam, the } \\
\text { Netherlands }\end{array}$ & $\begin{array}{l}\text { Data acquisition and revision } \\
\text { of the manuscript for } \\
\text { intellectual content }\end{array}$ \\
& $\begin{array}{l}\text { Alexander } \\
\text { Radbruch, } \\
\text { MD, JD }\end{array}$ & $\begin{array}{l}\text { Nepartment of } \\
\text { Hospital Bonn, Germany }\end{array}$ \\
\hline
\end{tabular}


Appendix (continued)

\begin{tabular}{|c|c|c|}
\hline Name & Location & Contribution \\
\hline $\begin{array}{l}\text { Bernd } \\
\text { Weber, MD }\end{array}$ & $\begin{array}{l}\text { Institute of Experimental } \\
\text { Epileptology and Cognition } \\
\text { Research, University Hospital } \\
\text { Bonn, Germany }\end{array}$ & $\begin{array}{l}\text { Revision of the manuscript for } \\
\text { intellectual content }\end{array}$ \\
\hline $\begin{array}{l}\text { Albert J. } \\
\text { Becker, } \\
\text { MD }\end{array}$ & $\begin{array}{l}\text { Section for Translational } \\
\text { Epilepsy Research, } \\
\text { Department of } \\
\text { Neuropathology, University } \\
\text { Hospital Bonn, Germany }\end{array}$ & $\begin{array}{l}\text { Revision of the manuscript for } \\
\text { intellectual content }\end{array}$ \\
\hline $\begin{array}{l}\text { Christian } \\
\text { E. Elger, } \\
\text { MD }\end{array}$ & $\begin{array}{l}\text { Department of Epileptology, } \\
\text { University Hospital Bonn, } \\
\text { Germany }\end{array}$ & $\begin{array}{l}\text { Data acquisition and revision } \\
\text { of the manuscript for } \\
\text { intellectual content }\end{array}$ \\
\hline $\begin{array}{l}\text { Rainer } \\
\text { Surges, } \\
\text { MD, PhD }\end{array}$ & $\begin{array}{l}\text { Department of Epileptology, } \\
\text { University Hospital Bonn, } \\
\text { Germany }\end{array}$ & $\begin{array}{l}\text { Data acquisition and revision } \\
\text { of the manuscript for } \\
\text { intellectual content }\end{array}$ \\
\hline $\begin{array}{l}\text { Theodor } \\
\text { Rüber, MD }\end{array}$ & $\begin{array}{l}\text { Department of Epileptology, } \\
\text { University Hospital Bonn, } \\
\text { Germany }\end{array}$ & $\begin{array}{l}\text { Data acquisition, design and } \\
\text { conceptualization of the } \\
\text { study, drafted and revised the } \\
\text { manuscript for intellectual } \\
\text { content, and study } \\
\text { supervision }\end{array}$ \\
\hline
\end{tabular}

\section{References}

1. Bien CG, Granata T, Antozzi C, et al. Pathogenesis, diagnosis and treatment of Rasmussen encephalitis: a European consensus statement. Brain. 2005;128(pt 3): 454-471.

2. Varadkar S, Bien CG, Kruse CA, et al. Rasmussen's encephalitis: clinical features, pathobiology, and treatment advances. Lancet Neurol. 2014;13(2):195-205.

3. Chiapparini L, Granata T, Farina L, et al. Diagnostic imaging in 13 cases of Rasmussen's encephalitis: can early MRI suggest the diagnosis? Neuroradiology. 2003;45(3):171-183.

4. Michelucci R, Pasini E, Marliani FA, Cirillo L. Teaching NeuroImages: diffusion tensor tractography of cortico-ponto-cerebellar pathways in Rasmussen encephalitis. Neurology. 2015;85(2):e15-e16.

5. Teixeira RA, Li LM, Santos SL, Zanardi VA, Guerreiro CA, Cendes F. Crossed cerebellar atrophy in patients with precocious destructive brain insults. Arch Neurol. 2002;59(5):843-847.

6. Takeoka M, Kim F, Caviness VS, Kennedy DN, Makris N, Holmes GL. MRI volumetric analysis in Rasmussen encephalitis: a longitudinal study. Epilepsia. 2003;44(2): 247-251.

7. Quesada CM, Urbach H, Elger CE, Bien CG. Rasmussen encephalitis with ipsilateral brain stem involvement in an adult patient. J Neurol Neurosurg Psychiatry. 2007;78(2): 200-201.

8. Moreira GP, Arantes P, Ono CR, Passarelli V, Castro LHM. Ipsilateral cerebellar atrophy and crossed ictal cerebellar diaschisis in a case of Rasmussen encephalitis. Clin Neurophysiol. 2018;129:e191.

9. Sansevere AJ, Henderson LA, Stredny CM, et al. Posterior-onset Rasmussen's encephalitis with ipsilateral cerebellar atrophy and uveitis resistant to rituximab. Epilepsy Behav Rep. 2020;14:100360.

10. Bien CG, Widman G, Urbach H, et al. The natural history of Rasmussen's encephalitis. Brain. 2002;125(8):1751-1759.

11. Van Essen DC, Ugurbil K, Auerbach E, et al. The Human Connectome Project: a data acquisition perspective. NeuroImage. 2012;62(4):2222-2231.

12. Diedrichsen J. A spatially unbiased atlas template of the human cerebellum. NeuroImage. 2006;33(1):127-138.
13. Ashburner J. A fast diffeomorphic image registration algorithm. NeuroImage. 2007; 38(1):95-113.

14. Winkler AM, Ridgway GR, Webster MA, Smith SM, Nichols TE. Permutation inference for the general linear model. NeuroImage. 2014;92(100):381-397.

15. Wagner J, Schoene-Bake JC, Bien CG, Urbach H, Elger CE, Weber B. Automated 3D MRI volumetry reveals regional atrophy differences in Rasmussen encephalitis. Epilepsia. 2012;53(4):613-621.

16. Smith SM, Jenkinson M, Woolrich MW, et al. Advances in functional and structural MR image analysis and implementation as FSL. NeuroImage. 2004;23(suppl 1): S208-S219.

17. Tournier JD, Smith R, Raffelt D, et al. MRtrix3: a fast, flexible and open software framework for medical image processing and visualisation. NeuroImage. 2019;202 116137.

18. Schilling KG, Blaber J, Huo Y, et al. Synthesized b0 for diffusion distortion correction (Synb0-DisCo). Magn Reson Imaging. 2019;64:62-70.

19. Andersson JL, Skare S, Ashburner J. How to correct susceptibility distortions in spinecho echo-planar images: application to diffusion tensor imaging. NeuroImage. 2003 20(2):870-888.

20. Andersson JLR, Sotiropoulos SN. An integrated approach to correction for offresonance effects and subject movement in diffusion MR imaging. NeuroImage. 2016; 125:1063-1078.

21. Tournier JD, Calamante F, Connelly A. Robust determination of the fibre orientation distribution in diffusion MRI: non-negativity constrained super-resolved spherical deconvolution. NeuroImage. 2007;35(4):1459-1472.

22. Smith RE, Tournier JD, Calamante F, Connelly A. Anatomically-constrained tractography: improved diffusion MRI streamlines tractography through effective use of anatomical information. NeuroImage. 2012;62(3):1924-1938.

23. Smith RE, Tournier JD, Calamante F, Connelly A. SIFT: spherical-deconvolution informed filtering of tractograms. NeuroImage. 2013;67:298-312.

24. Palesi F, De Rinaldis A, Castellazzi G, et al. Contralateral cortico-ponto-cerebellar pathways reconstruction in humans in vivo: implications for reciprocal cerebrocerebellar structural connectivity in motor and non-motor areas. Sci Rep. 2017;7(1) 12841.

25. Xu L, Groth KM, Pearlson G, Schretlen DJ, Calhoun VD. Source-based morphometry: the use of independent component analysis to identify gray matter differences with application to schizophrenia. Hum Brain Mapp. 2009;30(3):711-724.

26. Oyegbile TO, Bayless K, Dabbs K, et al. The nature and extent of cerebellar atrophy in chronic temporal lobe epilepsy. Epilepsia. 2011;52(4):698-706.

27. Ibdali M, Hadjivassiliou M, Grünewald RA, Shanmugarajah PD. Cerebellar degeneration in epilepsy: a systematic Review. IJERPH. 2021;18(2):473.

28. Belanoff JK, Gross K, Yager A, Schatzberg AF. Corticosteroids and cognition. J Psychiatr Res. 2001;35(3):127-145.

29. Mourelatos Z, McGarvey M, French JA, Wells G. October 2002: 27-year-old female with epilepsy. Brain Pathol. 2003;13(2):233-234.239.

30. Gupta PC, Rapin I, Houroupian DS, Roy S, Llena JF, Tandon PN. Smoldering encephalitis in children. Neuropediatrics. 1984;15(04):191-197.

31. AbdelRazek MA, Hillis JM, Guo Y, et al. Unilateral relapsing primary angiitis of the CNS: an entity suggesting differences in the immune response between the cerebral hemispheres. Neurol Neuroimmunol Neuroinflamm. 2021;8(2):e936.

32. Hart YM, Andermann F, Fish DR, et al. Chronic encephalitis and epilepsy in adult and adolescents: a variant of Rasmussen's syndrome? Neurology. 1997;48(2):418-424.

33. Schmitz-Hubsch T, du Montcel ST, Baliko L, et al. Scale for the assessment and rating of ataxia: development of a new clinical scale. Neurology. 2006;66(11):1717-1720.

34. Hoche F, Guell X, Vangel MG, Sherman JC, Schmahmann JD. The cerebellar cog nitive affective/Schmahmann syndrome scale. Brain. 2018;141(1):248-270.

35. Chen J, Liu J, Calhoun VD, et al. Exploration of scanning effects in multi-site structural MRI studies. J Neurosci Methods. 2014;230:37-50.

36. Benjamin RN, Thomas M, Muthusamy K, et al. Age-dependent reduction in severity and discrete topographical patterns in Rasmussen encephalitis: a link to cortical maturation? Pediatr Neurol. 2020;112:25-33.

37. Rudebeck SR, Shavel-Jessop S, Varadkar S, et al. Pre- and postsurgical cognitive trajectories and quantitative MRI changes in Rasmussen syndrome. Epilepsia. 2018; 59(6):1210-1219.

38. David B, Prillwitz CC, Hoppe C, et al. Morphometric MRI findings challenge the concept of the "unaffected" hemisphere in Rasmussen encephalitis. Epilepsia. 2019; 60(5):e40-e46. 


\title{
Neurology \\ Neuroimmunology \& Neuroinflammation
}

\author{
Infratentorial MRI Findings in Rasmussen Encephalitis Suggest Primary Cerebellar \\ Involvement \\ Johannes T. Reiter, Bastian David, Selma Enders, et al. \\ Neurol Neuroimmunol Neuroinflamm 2021;8; \\ DOI 10.1212/NXI.0000000000001058
}

This information is current as of August 13, 2021

Neurol Neuroimmunol Neuroinflamm is an official journal of the American Academy of Neurology.

Published since April 2014, it is an open-access, online-only, continuous publication journal. Copyright

Copyright (C) 2021 The Author(s). Published by Wolters Kluwer Health, Inc. on behalf of the American

Academy of Neurology.. All rights reserved. Online ISSN: 2332-7812.

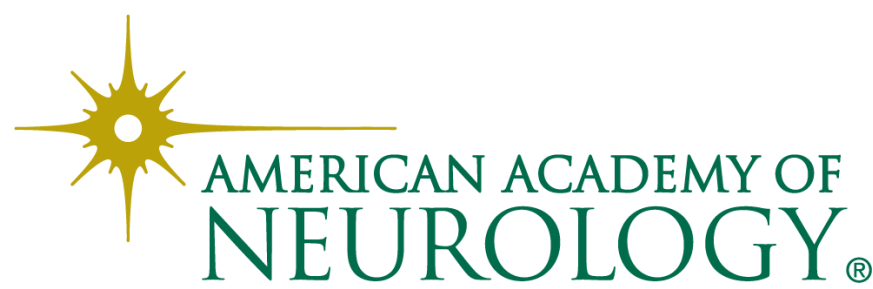




\section{Updated Information \& Services}

References

Citations

Subspecialty Collections

Permissions \& Licensing

Reprints including high resolution figures, can be found at: http://nn.neurology.org/content/8/6/e1058.full.html

This article cites 38 articles, 2 of which you can access for free at: http://nn.neurology.org/content/8/6/e1058.full.html\#\#ref-list-1

This article has been cited by 1 HighWire-hosted articles: http://nn.neurology.org/content/8/6/e1058.full.html\#\#otherarticles

This article, along with others on similar topics, appears in the following collection(s):

\section{All Pediatric}

http://nn.neurology.org//cgi/collection/all_pediatric

Autoimmune diseases

http://nn.neurology.org//cgi/collection/autoimmune_diseases

\section{Cerebellum}

http://nn.neurology.org//cgi/collection/cerebellum

\section{MRI}

http://nn.neurology.org//cgi/collection/mri

Volumetric MRI use in epilepsy

http://nn.neurology.org//cgi/collection/volumetric_mri_use_in_epileps $\mathrm{y}$

Information about reproducing this article in parts (figures,tables) or in its entirety can be found online at:

http://nn.neurology.org/misc/about.xhtml\#permissions

Information about ordering reprints can be found online:

http://nn.neurology.org/misc/addir.xhtml\#reprintsus

Neurol Neuroimmunol Neuroinflamm is an official journal of the American Academy of Neurology.

Published since April 2014, it is an open-access, online-only, continuous publication journal. Copyright

Copyright $\odot 2021$ The Author(s). Published by Wolters Kluwer Health, Inc. on behalf of the American

Academy of Neurology.. All rights reserved. Online ISSN: 2332-7812.

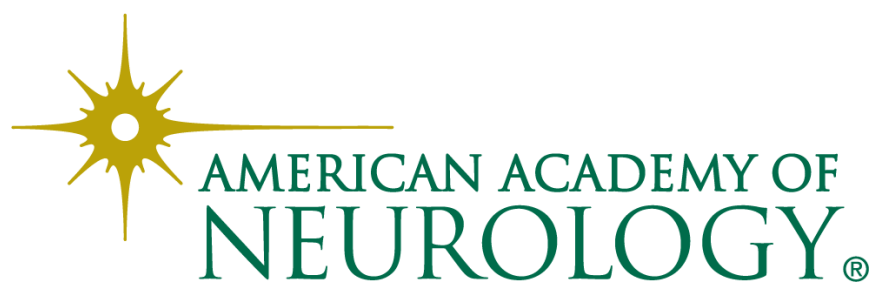

